\title{
EFICÁCIA De IMAZAPIC E Sulfentrazone sobre Cyperus rotundus EM Diferentes Condições de Chuva e Palha de CANa-de-Açúcar ${ }^{1}$
}

\author{
Efficacy of Imazapic and Sulfentrazone Applied on Cyperus rotundus under Different Rain and \\ Sugarcane Straw Conditions
}

\author{
SIMONI, F. ${ }^{2}$, VICTORIA FILHO, R. ${ }^{3}$, SAN MARTIN, H.A.M. ${ }^{2}$, SALVADOR, F.L. ${ }^{2}$, ALVES, A.S.R. ${ }^{2}$ e \\ BREMER NETO, H. ${ }^{2}$
}

\begin{abstract}
RESUMO - Nas áreas de colheita de cana-de-açúcar sem queima prévia (cana-crua), a presença da palha afeta a germinação de plantas daninhas e a dinâmica dos herbicidas. O presente trabalho foi conduzido com o objetivo de avaliar os efeitos do sulfentrazone e imazapic, associado à palha de cana-de-açúcar, com chuva após a aplicação dos herbicidas, no controle de Cyperus rotundus. O delineamento experimental adotado foi o de blocos casualizados no esquema fatorial $3 \times 3 \times 2 \times 2$, com quatro repetições, totalizando 144 parcelas. Os tratamentos foram conseqüência da combinação fatorial entre três níveis do fator palha de cana-de-açúcar (20, $10 \mathrm{t} \mathrm{ha}^{-1} \mathrm{e}$ ausência de cobertura morta sobre o solo); três níveis do fator herbicida (sulfentrazone a $800 \mathrm{~g} \mathrm{ha}^{-1}$, imazapic a $147 \mathrm{~g} \mathrm{ha}^{-1}$ e ausência de herbicida); dois níveis do fator intensidade de chuva (10 e $20 \mathrm{~mm}$ ); e dois níveis do fator épocas em que foram simuladas as chuvas após a aplicação dos herbicidas (24 e 168 horas). Avaliou-se o número de plantas por vaso, a massa seca da parte aérea e das estruturas do sistema subterrâneo e o número de tubérculos e bulbos sadios. Constatou-se que, no caso do herbicida sulfentrazone, a presença de $20 \mathrm{t} \mathrm{ha}^{-1}$ de palha de cana-de-açúcar diminuiu-lhe a eficácia. O herbicida imazapic teve bom desempenho tanto na ausência quanto na presença de palha e causou redução das variáveis estudadas, independentemente da intensidade de chuva. A intensidade de chuva de $10 \mathrm{~mm}$ não foi suficiente para transpor o herbicida sulfentrazone na quantidade de $20 \mathrm{t} \mathrm{ha}^{-1}$ de palha. Já a intensidade de $20 \mathrm{~mm}$ foi suficiente para lixiviar o herbicida até mesmo na maior quantidade de palha. $\mathrm{O}$ herbicida sulfentrazone suportou mais a permanência na palha, pois apresentou melhor eficácia em relação ao imazapic, quando a chuva foi simulada 168 horas após a aplicação dos herbicidas.
\end{abstract}

Palavras-chave: imazapic, intensidade de chuva, quantidade de palha, sulfentrazone, tiririca.

\begin{abstract}
In the raw sugarcane harvest areas, straw affects weed germination and herbicide dynamics. Thus, this work was developed to evaluate the effects of applying sulfentrazone and imazapic, associated with sugarcane straw and simulated rain for Cyperus rotundus control. The experiment was arranged in a randomized block design in a $3 \times 3 \times 2 \times 2$ factorial scheme with four repetitions, totaling 144 plots. The treatments were the result of a factorial combination of three levels of the factor sugarcane straw $\left(20,10 \mathrm{t} \mathrm{ha} \mathrm{H}^{-1}\right.$ and no dead cover on the soil); three levels of the factor herbicide (sulfentrazone at $800 \mathrm{~g} \mathrm{ha} 1$, imazapic at $147 \mathrm{~g} \mathrm{ha}^{-1}$ and no herbicide); two levels of the factor intensity of rainfall $(10$ and $20 \mathrm{~mm})$; and two levels of the factor simulated rain after herbicide application (24 and 168 hours). Number of plants per pot, dry mass of the aerial parts and underground system structures, and number of healthy tubers and bulbs were evaluated. Based on the results obtained, it was concluded that the presence of 20 tha of $^{-1}$ sugar cane straw reduced the efficacy of the herbicide sulfentrazone while the herbicide imazapic had a good performance with and without straw, causing a reduction in the varieties studied regardless of intensity of the rain. Rain intensity of $10 \mathrm{~mm}$, was not sufficient to surpass the herbicide sulfentrazone in the amount of $20 \mathrm{tha^{-1 }}$ of straw. However, $20 \mathrm{~mm}$ rain intensity was sufficient to cause herbicide leaching even at the largest amount of straw. The herbicide sulfentrazone showed a good resistance to straw since it was more efficacious than imazapic, when rain was simulated 168 hours after the application of the herbicides
\end{abstract}

Keywords: imazapic, intensity of rainfall, sugar cane straw quantity, sulfentrazone, purple nutsedge.

Recebido para publicação em 29.3.2006 e na forma revisada em 10.11.2006.

Pós-graduando em Fitotecnia da Escola Superior de Agricultura "Luiz de Queiroz" - ESALQ/USP, Av. Pádua Dias 11, Caixa Postal 9, 13417-950 Piracicaba-SP, <fesimoni@yahoo.com.br>; ${ }^{3}$ Prof. Dr. Titular do Dep. de Produção Vegetal, ESALQ/USP. 


\section{INTRODUÇÃO}

A área de produção de cana-de-açúcar destinada à colheita mecanizada sem queima prévia (cana-crua) tem crescido nas últimas décadas. A adoção desse sistema de colheita tem resultado em importantes modificações nas técnicas de cultivo, como o uso de maiores espaçamentos e a deposição de palha sobre o solo, que influenciam diretamente a ocorrência e o manejo de plantas daninhas (Velini \& Negrisoli, 2000).

Um dos maiores problemas no cultivo da cana-de-açúcar é a interferência das plantas daninhas que infestam as áreas cultivadas, competindo com a cultura por luz, nutrientes, água e espaço, provocando sérias perdas na produtividade (Victoria Filho \& Christoffoleti, 2004).

A espécie de planta daninha mais agressiva na cultura da cana-de-açúcar é a tiririca (Cyperus rotundus) (Bendixen \& Nandihalli, 1987), considerada uma das dez plantas daninhas mais agressivas do mundo.

Uma vez introduzida em uma nova área, a eliminação da tiririca é bastante difícil, e o mais preocupante é a grande velocidade com que se dissemina para áreas não-infestadas (Lorenzi, 1986).

Nas áreas de colheita de cana-crua, a presença da palha afeta a germinação de plantas daninhas e a dinâmica dos herbicidas (Christoffoleti et al., 2004). A palhada proporciona cobertura do solo, o que dificulta a emergência de plantas daninhas, pois reduz a penetração de luz no solo; também pode ocorrer a liberação de exsudados da palhada, os quais podem apresentar efeitos alelopáticos sobre a germinação de propágulos de plantas daninhas (Procópio et al., 2003). Contudo, a palha também pode limitar o uso de herbicidas em pré-emergência, os quais não atingem o solo (Christoffoleti et al., 2004).

A dinâmica dos herbicidas é um fator ainda pouco estudado no sistema de colheita de cana-crua. O comportamento de herbicidas residuais aplicados sobre a palha não depende apenas das características específicas do produto, mas também da quantidade e origem da cobertura morta, do volume de água e da época da primeira irrigação ocorrida após aplicação do produto, assim como das irrigações subseqüentes e das condições climáticas prevalecentes durante e após a aplicação (Rodrigues, 1993).

Medeiros \& Christoffoleti (2002) avaliaram o efeito da intensidade de chuva e da quantidade de palha de cana-de-açúcar sobre a eficácia de herbicidas e concluíram que a transposição dos herbicidas estudados através da palha de cana-de-açúcar é aumentada com a ocorrência de chuvas a partir de $10 \mathrm{~mm}$, em um período de 24 horas após pulverização.

Os poucos trabalhos com manejo de herbicidas em cana-crua parecem indicar que camadas de palha inferiores a $5 \mathrm{t} \mathrm{ha}^{-1}$ são suficientes para impedir a ação de herbicidas aplicados em pré-emergência, mas não impedem a germinação de grande número de plantas daninhas (Procópio et al., 2003).

Martins et al. (1999) verificaram que a cobertura do solo com diferentes quantidades de palha afetou a germinação de algumas espécies de plantas daninhas. Entretanto, para a tiririca a barreira de palha não inibiu totalmente a brotação e a formação da parte aérea. De acordo com Durigan et al. (2004), especificamente para a tiririca é falsa a impressão de que a barreira de palha possa inibir totalmente a sua brotação e a formação de manifestações epígeas.

Segundo Victoria Filho (1993), o manejo da palha residual da colheita, juntamente com o uso combinado de herbicidas, constitui-se em técnica eficaz para o controle das plantas daninhas. Somente um programa integrado de controle representa a melhor forma de diminuição das perdas, já que a seleção das plantas daninhas, em função da competição, faz com que as infestantes apresentem-se muito mais aptas à obtenção de recursos do meio, quando comparadas às espécies cultivadas (Gomide, 1993).

O presente trabalho teve por objetivo avaliar a influência da intensidade de chuva e da quantidade de palha de cana-de-açúcar sobre a eficácia dos herbicidas sulfentrazone e imazapic aplicados em pré-emergência para controle de Cyperus rotundus. 


\section{MATERIAL E MÉTODOS}

O experimento foi conduzido em casa de vegetação do Departamento de Produção Vegetal da ESALQ/USP, em Piracicaba-SP, entre 31/8/2005 e 31/10/2006.

O delineamento experimental adotado foi o de blocos casualizados no esquema fatorial $3 \times 3 \times 2 \times 2$, com quatro repetições, totalizando 144 parcelas. Os tratamentos foram conseqüência da combinação fatorial entre três níveis do fator palha de cana-de-açúcar $\left(20,10\right.$ t ha $^{-1}$ e ausência de cobertura morta sobre o solo); três níveis do fator herbicida (sulfentrazone a $800 \mathrm{~g} \mathrm{ha}^{-1}$, imazapic a $147 \mathrm{~g} \mathrm{ha}^{-1} \mathrm{e}$ ausência de herbicida); dois níveis do fator intensidade de chuva (10 e $20 \mathrm{~mm}$ ); e dois níveis do fator épocas em que foram simuladas as chuvas após a aplicação dos herbicidas (24 e 168 horas).

As parcelas constaram de vasos com capacidade para $3 \mathrm{~L}$, preenchidos com solo do tipo Latossolo Vermelho-Escuro Mesotrófico, proveniente da Usina Costa Pinto, Grupo Cosan, Piracicaba-SP. O solo foi coletado em área infestada com tiririca e, posteriormente, peneirado, com a finalidade de retirar tubérculos. Estes foram separados quanto ao tamanho, sendo utilizados aqueles de tamanho médio, com massa fresca entre 0,4 e 1,0 g. As características químicas do solo são apresentadas na Tabela 1. Em cada parcela, foram plantados sete tubérculos sadios, na profundidade de 0,03 m.

A palha de cana-de-açúcar utilizada foi da variedade RB 84-5210, sendo esta colhida logo após o corte mecânico, em área da Usina Costa Pinto - Grupo Cosan, Piracicaba-SP.

Para aplicação dos herbicidas foi utilizada câmara de pulverização à pressão constante de $2 \mathrm{kgf} \mathrm{cm}^{-2}$, equipada com barra de aplicação contendo uma ponta de pulverização do tipo leque, modelo TeeJet 80.02, posicionada a uma altura de $0,50 \mathrm{~m}$ da superfície dos vasos, proporcionando um consumo relativo de calda de $200 \mathrm{~L} \mathrm{ha}^{-1}$.

Às 24 e 168 horas após a aplicação dos herbicidas, foram simuladas chuvas nas intensidades de 10 e $20 \mathrm{~mm}$, e a cada sete dias foi realizada irrigação de acordo com a média histórica dos meses em que o experimento foi conduzido (setembro - 62,0 mm; outubro - 110,7 mm), de maneira a simular a chuva em condições de campo. As médias históricas de precipitações pluviais são apresentadas na Figura 1.

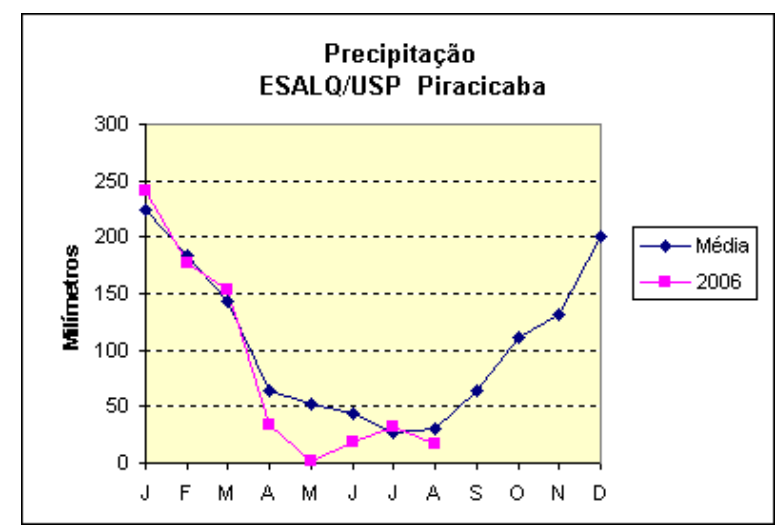

Figura 1 - Histórico de precipitações pluviais. Piracicaba-SP.

Foram realizadas avaliações do número de plantas por vaso aos 30 e 60 dias após o plantio (DAP). Aos 60 DAP, retirou-se a palha, a parte aérea foi cortada rente ao solo e avaliou-se sua massa seca. O sistema subterrâneo foi lavado com água sob pressão, para retirada da terra,

Tabela 1 - Resultados da análise química de amostra de solo coletada na camada de 0 a 0,25 m. Piracicaba-SP, 2004

\begin{tabular}{|c|c|c|c|c|c|c|c|c|c|}
\hline $\mathrm{P}$ & $\mathrm{MO}$ & $\mathrm{pH}$ & $\mathrm{K}$ & $\mathrm{Ca}$ & $\mathrm{Mg}$ & $\mathrm{Al}$ & $\mathrm{CTC}$ & $\mathrm{V}$ & $\mathrm{M}$ \\
\hline$\left(\mathrm{mg} \mathrm{dm}^{-3}\right)$ & $\left(\mathrm{g} \mathrm{dm}^{-3}\right)$ & $\left(\mathrm{CaCl}_{2}\right)$ & \multicolumn{7}{|c|}{$\left(\mathrm{mmol}_{\mathrm{c}} \mathrm{dm}^{-3}\right)$} \\
\hline 30 & 23 & 5,1 & 1,3 & 54 & 28 & 3 & 129 & 64 & 3 \\
\hline
\end{tabular}

$\mathrm{MO}=$ matéria orgânica; $\mathrm{CTC}=$ capacidade de troca catiônica; $\mathrm{V}=$ saturação por base; $\mathrm{M}$ = saturação por alumínio. 
seco em papel absorvente, separado nas diferentes estruturas (bulbos basais, rizomas + raiz e tubérculos) e foi avaliado o número de cada estrutura e suas massas secas. Para determinar a massa seca, as estruturas da parte aérea e do sistema subterrâneo foram secas em estufa sob ventilação forçada a 65-70 ${ }^{\circ} \mathrm{C}$, até atingir massa constante.

Os dados foram submetidos à análise de variância, em esquema fatorial $3 \times 3 \times 2 \times 2$, com aplicação do teste F. Em seguida, aplicouse o teste de Tukey a 5\% de probabilidade. Os dados sobre número de plantas, de tubérculos e de bulbos foram submetidos à transformação pela raiz quadrada de $\mathrm{x}+0,5$.

\section{RESULTADOS E DISCUSSÃO}

As interações que se apresentaram significativas ao teste $\mathrm{F}$ foram: quantidade de palha $\mathrm{x}$ herbicidas, quantidade de palha $\mathrm{x}$ intensidade de chuva, quantidade de palha x época em que foi simulada a chuva, herbicidas $\mathrm{x}$ intensidade de chuva e herbicidas x época em que foi simulada a chuva.

A interação da quantidade de palha e dos herbicidas proporcionou efeito no número de plantas de tiririca avaliadas aos 60 dias após o plantio (DAP), no número de bulbos e na massa seca de bulbos, rizoma + raiz e parte aérea.

O número de plantas aos 60 DAP não foi afetado pelas quantidades de palha em quaisquer herbicidas. Os herbicidas tiveram efeito significativo, proporcionando redução no número de plantas de tiririca aos 60 DAP. No tratamento em que não se aplicou herbicida, pode-se observar maior número de plantas, não havendo diferença entre os herbicidas sulfentrazone e imazapic em todas as quantidades de palha (Tabela 2).

Martins et al. (1999) e Durigan et al. (2004) observaram resultados semelhantes, em que a adição de palha sobre a superfície do solo não afetou o número de plantas de tiririca.

Christoffoleti et al. (1995) conduziram um experimento em que foi avaliada a eficácia do herbicida sulfentrazone (700 $\mathrm{g} \mathrm{ha}^{-1}$ ) no controle da tiririca e constataram que o herbicida proporcionou controle superior a $80 \%$, aos 60 dias após sua aplicação. Em relação ao controle de tiririca pelo herbicida imazapic, Christoffoleti et al. (2002) obtiveram controle da parte aérea maior que $80 \%$ quando foram aplicadas as doses de 105, 126 e $147 \mathrm{~g} \mathrm{ha}^{-1}$. Resultados similares foram observados por Medeiros et al. (2004), os quais constataram que o herbicida imazapic, na dose de $147 \mathrm{~g} \mathrm{ha}^{-1}$, alcançou excelente controle de tiririca tanto na ausência quanto na presença de palha.

No que se refere ao número de bulbos, pode-se observar que estes não foram afetados pelas quantidades de palha com quaisquer dos herbicidas (Tabela 2). Esses resultados são

Tabela 2 - Efeito da interação entre a quantidade de palha de cana-de-açúcar adicionada ao solo e os herbicidas no número de plantas de tiririca, no número de bulbos basais, na massa seca de bulbos basais, na massa seca de rizoma + raiz e na massa seca da parte aérea, aos 60 DAP. Piracicaba-SP, 2005

\begin{tabular}{|c|c|c|c|}
\hline $\begin{array}{l}\text { Quantidade } \\
\text { de palha }\end{array}$ & \multicolumn{3}{|c|}{ Herbicida } \\
\hline$\left(\right.$ t ha $\left.^{-1}\right)$ & Sem herbicida & Sulfentrazone & Imazapic \\
\hline & \multicolumn{3}{|c|}{ Número de plantas ${ }^{1 /}$} \\
\hline 0 & $3,72 \mathrm{aA}^{2 /}$ & $1,58 \mathrm{bA}$ & $1,98 \mathrm{bA}$ \\
\hline 10 & $4,01 \mathrm{aA}$ & $1,38 \mathrm{bA}$ & $1,98 \mathrm{bA}$ \\
\hline \multirow[t]{3}{*}{20} & 3,64 aA & $2,34 \mathrm{bA}$ & $1,68 \mathrm{bA}$ \\
\hline & \multicolumn{2}{|c|}{$\mathrm{CV}(\%) 31,24$} & $\mathrm{~F} 4,12$ \\
\hline & \multicolumn{3}{|c|}{ Número de bulbos basais ${ }^{1 /}$} \\
\hline 0 & $3,56 \mathrm{aA}^{2} \stackrel{2}{\prime}$ & $1,62 \mathrm{bA}$ & $1,84 \mathrm{bA}$ \\
\hline 10 & $4,16 \mathrm{aA}$ & $1,11 \mathrm{cA}$ & $2,29 \mathrm{bA}$ \\
\hline \multirow[t]{3}{*}{20} & $3,99 \mathrm{aA}$ & $2,28 \mathrm{bA}$ & $2,44 \mathrm{bA}$ \\
\hline & \multicolumn{2}{|c|}{$\mathrm{CV}(\%) 35,72$} & F 2,67 \\
\hline & \multicolumn{3}{|c|}{ Massa seca de bulbos basais } \\
\hline 0 & $0,80 \mathrm{aB}^{\frac{1}{1}}$ & $0,14 \mathrm{bA}$ & $0,08 \mathrm{bA}$ \\
\hline 10 & $1,62 \mathrm{aA}$ & $0,03 \mathrm{bA}$ & $0,38 \mathrm{bA}$ \\
\hline \multirow[t]{3}{*}{20} & $1,54 \mathrm{aA}$ & $0,32 \mathrm{bA}$ & $0,82 \mathrm{bA}$ \\
\hline & \multicolumn{2}{|c|}{$\mathrm{CV}(\%) 76,37$} & $\mathrm{~F} 4,45$ \\
\hline & \multicolumn{3}{|c|}{ Massa seca de rizoma + raiz } \\
\hline 0 & $0,97 \mathrm{aA}^{\frac{1}{}}$ & $0,29 \mathrm{bA}$ & $0,03 \mathrm{bA}$ \\
\hline 10 & $1,30 \mathrm{aA}$ & $0,08 \mathrm{bA}$ & $0,13 \mathrm{bA}$ \\
\hline \multirow[t]{3}{*}{20} & $0,98 \mathrm{aA}$ & $0,49 \mathrm{bA}$ & $0,39 \mathrm{bA}$ \\
\hline & \multicolumn{2}{|c|}{$\mathrm{CV}(\%) 71,73$} & F 4,83 \\
\hline & \multicolumn{3}{|c|}{ Massa seca da parte aérea } \\
\hline 0 & $2,32 \mathrm{aB}^{\frac{1}{1}}$ & $0,53 \mathrm{bB}$ & $0,41 \mathrm{bA}$ \\
\hline 10 & $4,66 \mathrm{aA}$ & $0,56 \mathrm{bB}$ & $0,76 \mathrm{bA}$ \\
\hline \multirow[t]{2}{*}{20} & $4,12 \mathrm{aA}$ & $1,80 \mathrm{bA}$ & $1,19 \mathrm{bA}$ \\
\hline & \multicolumn{2}{|c|}{$\mathrm{CV}(\%) 43,12$} & 11,33 \\
\hline
\end{tabular}

I/ Médias seguidas por letras iguais, minúsculas na linha ou maiúsculas na coluna, não diferem entre si pelo teste de Tukey a $5 \% .{ }^{2 /}$ Os dados foram transformados em raiz de $\mathrm{x}+0,5$ para análise estatística. 
contrários aos encontrados por Novo (2004), o qual menciona que a adição de quantidades crescentes de palha de cana-de-açúcar no solo causou redução no número de bulbos.

Os tratamentos em que foram aplicados os dois herbicidas apresentaram menor número de bulbos de tiririca em todas as quantidades de palha em relação ao tratamento em que não foi aplicado herbicida. Apenas na quantidade de 10 t ha $^{-1}$ houve diferença entre os herbicidas sulfentrazone e imazapic: observou-se menor número de bulbos para o primeiro (Tabela 2). De acordo com esse resultado, pode-se dizer que o herbicida sulfentrazone apresentou melhor eficácia em relação ao imazapic, na quantidade de $10 \mathrm{t} \mathrm{ha}^{-1}$ de palha de canade-açúcar. Medeiros (2001) observou esse mesmo resultado, concluindo que o herbicida sulfentrazone tem sua eficácia reduzida em função da presença de grandes quantidades de palha.

Hernandez et al. (2001) observaram que a eficácia do imazapic depende da dose aplicada (122,5 e $\left.147 \mathrm{~g} \mathrm{ha}^{-1}\right)$, independentemente da presença da palha de cana-de-açúcar inclusive para a espécie Cyperus rotundus. Durigan et al. (2004) testaram vários herbicidas para o controle da tiririca, com e sem cobertura do solo pela palha da cana-de-açúcar, e verificaram que os melhores resultados de controle foram proporcionados pelos herbicidas sulfentrazone $\left(700 \mathrm{~g} \mathrm{ha}^{-1}\right)$ e imazapic (105 $\left.\mathrm{g} \mathrm{ha}^{-1}\right)$, sem a cobertura de palha.

Apenas no tratamento em que não foi aplicado herbicida houve efeito da quantidade de palha na massa seca de bulbos, observandose menor massa quando não foi adicionada palha, pelo fato de esta proporcionar retenção maior da umidade no solo por maior período de tempo. Em todas as quantidades de palha verificou-se maior massa seca de bulbos no tratamento sem herbicida, não havendo diferença entre os herbicidas sulfentrazone e imazapic (Tabela 2).

Para massa seca de rizoma + raiz não houve efeito das quantidades de palha. A maior massa seca de rizoma + raiz foi observada no tratamento em que não foi aplicado herbicida para todas as quantidades de palha, não havendo diferença entre sulfentrazone e imazapic (Tabela 2).
De acordo com a Tabela 2, observa-se que para a massa seca da parte aérea houve efeito da quantidade de palha no tratamento sem herbicida e no tratamento em que foi aplicado sulfentrazone. No tratamento sem herbicida, a maior redução da massa seca da parte aérea ocorreu quando não se adicionou palha sobre o solo, e no tratamento em que foi aplicado sulfentrazone a maior redução ocorreu quando não se adicionou palha e quando foram adicionados $10 \mathrm{t} \mathrm{ha}^{-1}$ de palha sobre o solo, não havendo diferença significativa entre essas duas quantidades de palha. O tratamento sem aplicação de herbicida apresentou maior massa seca em todas as quantidades de palha, não havendo diferença significativa entre sulfentrazone e imazapic. Pode-se observar que, para o herbicida sulfentrazone, a presença de $20 \mathrm{t} \mathrm{ha}^{-1}$ de palha reduziu a eficácia do herbicida, para a variável massa seca da parte aérea. Medeiros (2001) observou o mesmo resultado para as variáveis rebrota e número de tubérculos de tiririca e concluiu que o herbicida sulfentrazone tem sua eficácia reduzida em função da presença de grande quantidade de palha (15 $\left.\mathrm{t} \mathrm{ha}^{-1}\right)$.

Segundo Teasdale \& Mohler (1993), em locais onde a umidade do solo seria o principal fator limitante à germinação de sementes de plantas daninhas, a maior conservação da umidade no solo causada pelos resíduos de colheita poderia propiciar um ambiente mais favorável à emergência. Na presente pesquisa, a presença da palha na superfície, embora não tenha influído significativamente no número de plantas, aumentou a massa seca da parte aérea, como se observa na Tabela 2.

A interação da quantidade de palha e intensidade de chuva afetou o número e a massa seca de bulbos. Para o número de bulbos, observa-se que, em relação à quantidade de palha, houve maior número de bulbos para a quantidade de $20 \mathrm{t} \mathrm{ha}^{-1}$, com irrigação de $10 \mathrm{~mm}$. Apenas com a adição de $20 \mathrm{t} \mathrm{ha}^{-1}$ de palha houve diferença significativa entre as intensidades de chuva, havendo maior número de bulbos na irrigação de $10 \mathrm{~mm}$ (Tabela 3). Pelos resultados obtidos, é provável que a irrigação de $10 \mathrm{~mm}$ não tenha sido suficiente para transpor o herbicida na quantidade de $20 \mathrm{t} \mathrm{ha}^{-1}$ de palha, apresentando maior número de bulbos nessa condição. Na intensidade 
de chuva de 20 mm não houve diferença entre as quantidades de palha, mostrando que $20 \mathrm{~mm}$ de chuva foram suficientes para fazer com que o herbicida atingisse o solo. Negrisoli et al. (2004) também observaram bom controle da tiririca através do herbicida sulfentrazone com a simulação de chuva a partir de $20 \mathrm{~mm}$. Marim et al. (1979) relataram que os herbicidas propachlor, atrazina, alachlor e cyanazine, quando aplicados em palhada de milho, não foram fortemente adsorvidos; metade ou mais da quantidade inicial aplicada foi lixiviada após irrigação de 20 mm de água.

Para massa seca de bulbos, pode-se observar que, em relação à quantidade de palha, ocorreu maior massa quando foram adicionados $20 \mathrm{t} \mathrm{ha}^{-1}$ de palha na intensidade de chuva de $10 \mathrm{~mm}$, evidenciando que essa precipitação não foi suficiente para lixiviar o herbicida. Em se tratando das intensidades de chuva, não houve diferença entre $10 \mathrm{e}$ $20 \mathrm{~mm}$ para quaisquer quantidades de palha (Tabela 3).

A interação da quantidade de palha e época em que foi simulada a chuva após a aplicação dos herbicidas afetou a massa seca de rizoma + raiz. Observou-se menor massa apenas quando a chuva foi simulada 168 horas após a aplicação dos herbicidas, no tratamento em que não foi adicionada palha, não havendo diferença entre 10 e 20 t ha $^{-1}$. Verificou-se que a massa seca de rizoma + raiz foi afetada pela época em que foi realizada a simulação de chuva quando não foi adicionada palha, apresentando maior massa quando a irrigação foi feita 24 horas após a aplicação dos herbicidas (Tabela 4). Supõe-se que a disponibilidade de umidade no solo no período inicial de avaliação tenha permitido melhor desenvolvimento das plantas de tiririca.

A interação entre herbicidas e intensidade de chuva afetou o número de plantas de tiririca aos 60 DAP, o número de bulbos, a massa seca de bulbos, a massa seca de rizoma + raiz e a massa seca da parte aérea.

O número de plantas foi afetado pelos herbicidas, sendo observado maior número de plantas de tiririca aos 60 DAP no tratamento em que não foi aplicado herbicida em qualquer intensidade de chuva. Para o herbicida sulfentrazone houve diferença significativa entre as intensidades de chuva, apresentando maior número de plantas com a irrigação de $10 \mathrm{~mm}$, evidenciando que esta irrigação foi insuficiente para transpor o herbicida na palha - necessário para melhor eficácia do herbicida (Tabela 5). Medeiros \& Christoffoleti (2002) observaram que a transposição dos herbicidas através da palha de cana-de-açúcar é aumentada com a ocorrência de chuvas a partir de 10 mm; Negrisoli et al. (2004) também observaram excelente controle de $C$. rotundus pelo herbicida sulfentrazone com $20 \mathrm{~mm}$ de chuva.

Tabela 3 - Efeito da interação entre a quantidade de palha de cana-de-açúcar adicionada ao solo e a intensidade de chuva no número e na massa seca de bulbos basais, aos 60 DAP. Piracicaba-SP, 2005

\begin{tabular}{|c|c|c|}
\hline Quantidade de palha & \multicolumn{2}{|c|}{ Intensidade de chuva } \\
\hline$\left(\mathrm{t} \mathrm{ha}^{-1}\right)$ & $10 \mathrm{~mm}$ & $20 \mathrm{~mm}$ \\
\hline & \multicolumn{2}{|c|}{ Número de bulbos basais $^{1 /}$} \\
\hline 0 & $2,58 \mathrm{aB} \stackrel{2 l}{\cdots}$ & $2,10 \mathrm{aA}$ \\
\hline 10 & $2,48 \mathrm{aB}$ & $2,56 \mathrm{aA}$ \\
\hline \multirow[t]{3}{*}{20} & $3,38 \mathrm{aA}$ & $2,42 \mathrm{bA}$ \\
\hline & CV (\%) 35,72 & F 3,84 \\
\hline & \multicolumn{2}{|c|}{ Massa seca de bulbos basais } \\
\hline 0 & $0,29 \mathrm{aB}^{\mathbf{1}^{\prime}}$ & $0,40 \mathrm{aA}$ \\
\hline 10 & $0,53 \mathrm{aB}$ & $0,82 \mathrm{aA}$ \\
\hline \multirow{2}{*}{20} & $1,00 \mathrm{aA}$ & $0,79 \mathrm{aA}$ \\
\hline & CV (\%) 76,37 & F 3,18 \\
\hline
\end{tabular}

1/ Médias seguidas por letras iguais, minúsculas na linha ou maiúsculas na coluna, não diferem entre si pelo teste de Tukey a $5 \% . \stackrel{2 /}{=}$ Os dados foram transformados em raiz de $\mathrm{x}+0,5$ para análise estatística.

Tabela 4 - Efeito da interação entre a quantidade de palha de cana-de-açúcar adicionada ao solo e a época em que foi simulada a chuva após a aplicação dos herbicidas na massa seca de rizoma + raiz, aos 60 DAP. Piracicaba-SP, 2005

\begin{tabular}{|c|c|c|}
\hline Quantidade de palha & \multicolumn{2}{|c|}{ Época em que foi simulada a chuva } \\
\hline$\left(\mathrm{t} \mathrm{ha}^{-1}\right)$ & 24 horas & 168 horas \\
\hline & \multicolumn{2}{|c|}{ Massa seca de rizoma + raiz } \\
\hline 0 & $0,65 \mathrm{aA}^{1}$ & $0,21 \mathrm{bB}$ \\
\hline 10 & $0,48 \mathrm{aA}$ & $0,53 \mathrm{aA}$ \\
\hline 20 & $0,66 \mathrm{aA}$ & $0,58 \mathrm{aA}$ \\
\hline & $\mathrm{CV}(\%) 71,73$ & $\mathrm{~F} 5,55$ \\
\hline
\end{tabular}

1/ Médias seguidas por letras iguais, minúsculas na linha ou maiúsculas na coluna, não diferem entre si pelo teste de Tukey a $5 \%$. 
Tabela 5 - Efeito da interação entre os herbicidas e a intensidade de chuva no número de plantas, no número de bulbos basais, na massa seca de bulbos basais, na massa seca de rizoma + raiz e na massa seca da parte aérea, aos 60 DAP. Piracicaba-SP, 2005

\begin{tabular}{|c|c|c|}
\hline \multirow{2}{*}{ Herbicida } & \multicolumn{2}{|c|}{ Intensidade de chuva } \\
\hline & $10 \mathrm{~mm}$ & $20 \mathrm{~mm}$ \\
\hline & \multicolumn{2}{|c|}{ Número de plantas ${ }^{\underline{1} /}$} \\
\hline Sem herbicida & $3,77 \mathrm{aA}^{2 !}$ & $3,81 \mathrm{aA}$ \\
\hline Sulfentrazone & $2,23 \mathrm{aB}$ & $1,30 \mathrm{bB}$ \\
\hline \multirow[t]{3}{*}{ Imazapic } & $2,13 \mathrm{aB}$ & $1,64 \mathrm{aB}$ \\
\hline & $\mathrm{CV}(\%) 31,24$ & F 4,69 \\
\hline & \multicolumn{2}{|c|}{ Número de bulbos basais $\stackrel{\mathbb{1}}{ }$} \\
\hline Sem herbicida & $3,77 \mathrm{aA}^{2} !$ & $4,03 \mathrm{aA}$ \\
\hline Sulfentrazone & $2,18 \mathrm{aB}$ & $1,16 \mathrm{bB}$ \\
\hline \multirow[t]{3}{*}{ Imazapic } & $2,49 \mathrm{aB}$ & $1,89 \mathrm{aB}$ \\
\hline & $\mathrm{CV}(\%) 35,72$ & F 5,94 \\
\hline & \multicolumn{2}{|c|}{ Massa seca de bulbos basais } \\
\hline Sem herbicida & $1,06 \mathrm{bA}^{1 / \prime}$ & $1,59 \mathrm{aA}$ \\
\hline Sulfentrazone & $0,24 \mathrm{aB}$ & $0,09 \mathrm{aB}$ \\
\hline \multirow[t]{3}{*}{ Imazapic } & $0,52 \mathrm{aB}$ & $0,34 \mathrm{aB}$ \\
\hline & $\mathrm{CV}(\%) 76,37$ & F 8,20 \\
\hline & \multicolumn{2}{|c|}{ Massa seca de rizoma + raiz } \\
\hline Sem herbicida & $0,83 \mathrm{bA}^{1 /}$ & $1,34 \mathrm{aA}$ \\
\hline Sulfentrazone & $0,29 \mathrm{aB}$ & $0,28 \mathrm{aB}$ \\
\hline \multirow[t]{3}{*}{ Imazapic } & $0,29 \mathrm{aB}$ & $0,09 \mathrm{aB}$ \\
\hline & $\mathrm{CV}(\%) 71,73$ & F 11,61 \\
\hline & \multicolumn{2}{|c|}{ Massa seca da parte aérea } \\
\hline Sem herbicida & $3,78 \mathrm{aA}^{1 / 1}$ & $3,62 \mathrm{aA}$ \\
\hline Sulfentrazone & $1,41 \mathrm{aB}$ & $0,52 \mathrm{bB}$ \\
\hline \multirow[t]{2}{*}{ Imazapic } & $1,19 \mathrm{aB}$ & $0,38 \mathrm{aB}$ \\
\hline & CV (\%) 43,12 & F 3,12 \\
\hline
\end{tabular}

1/ Médias seguidas por letras iguais, minúsculas na linha ou maiúsculas na coluna, não diferem entre si pelo teste de Tukey a 5\%. ${ }^{2 /}$ Os dados foram transformados em raiz de $\mathrm{x}+0,5$ para análise estatística.

Resultados semelhantes foram obtidos em relação ao número de bulbos, não havendo diferença entre os herbicidas sulfentrazone e imazapic, para quaisquer intensidades de chuva. Apenas o herbicida sulfentrazone mostrou diferença entre as intensidades de chuva, com maior número de bulbos na irrigação de $10 \mathrm{~mm}$ (Tabela 5). Pode-se também verificar nesta tabela que a intensidade de chuva de $20 \mathrm{~mm}$ proporcionou maior transposição do herbicida sulfentrazone, provocando maior redução no número de bulbos de tiririca.

A massa seca de bulbos foi afetada pelos herbicidas, apresentando maior massa no tratamento sem aplicação de herbicida, não havendo diferença entre os herbicidas sulfentrazone e imazapic, em ambas as intensidades de chuva. Em relação à intensidade de chuva, apenas houve efeito no tratamento em que não foi aplicado herbicida, o qual mostrou menor massa quando foram aplicados $10 \mathrm{~mm}$ de chuva (Tabela 5). Provavelmente, a maior disponibilidade de umidade do solo tenha afetado o desenvolvimento dos bulbos.

A massa seca de rizoma + raiz foi afetada pelos herbicidas, ocorrendo maior massa no tratamento em que não foi aplicado herbicida em qualquer intensidade de chuva. A intensidade de chuva apenas causou efeito no tratamento sem herbicida, em que se constatou menor massa seca de rizoma + raiz na intensidade de $10 \mathrm{~mm}$ (Tabela 5).

Para massa seca da parte aérea, o tratamento sem aplicação de herbicida apresentou a maior massa em qualquer intensidade de chuva, e os herbicidas sulfentrazone e imazapic provocaram redução da massa seca da parte aérea, não diferindo entre si. Apenas o herbicida sulfentrazone foi sensivel ao efeito da intensidade de chuva, em que a menor massa foi verificada quando se aplicaram $20 \mathrm{~mm}$ de chuva. Esse resultado mostra que, para o herbicida sulfentrazone, a intensidade de chuva de $20 \mathrm{~mm}$ mostrou maior redução na massa seca da parte aérea. Em relação ao herbicida imazapic, pode-se observar que houve redução da massa seca da parte aérea, independentemente da intensidade de chuva aplicada (Tabela 5).

Medeiros et al. (2004) obtiveram resultados semelhantes, constatando que o herbicida imazapic apresentou excelente transposição através da palha de cana, independentemente da quantidade de água (10 ou $20 \mathrm{~mm}$ ) aplicada após a pulverização do herbicida.

A interação entre herbicidas e época em que foi simulada a chuva afetou o número de plantas aos 60 DAP, o número de bulbos e a massa seca de rizoma + raiz.

Na Tabela 6, pode-se verificar que para o número de plantas aos $60 \mathrm{DAP}$ não houve diferença significativa entre as épocas em que foi simulada a chuva para quaisquer tratamentos herbicidas. Observa-se maior número de plantas de tiririca aos 60 DAP no 
tratamento em que não foi aplicado herbicida, havendo diferença entre o herbicida imazapic e sulfentrazone apenas quando a chuva foi simulada 168 horas após a aplicação deles. Quando a chuva foi simulada 24 horas após a aplicação dos herbicidas, estes apresentaram diferença em relação à testemunha, porém não se diferenciaram entre si. O tratamento que ocasionou maior redução do número de plantas foi o herbicida sulfentrazone quando a chuva foi simulada 168 horas após a sua aplicação. Os resultados mostram que este herbicida apresenta melhor eficácia quando a irrigação é realizada 168 horas depois da sua aplicação, evidenciando que ele suporta por mais tempo a permanência na palha.

Negrisoli et al. (2004) observaram excelente controle de $C$. rotundus por sulfentrazone, com $20 \mathrm{~mm}$ de chuva aplicada um dia após aplicação do herbicida, independentemente das doses testadas.

O número de bulbos foi afetado pelos herbicidas, e maior número foi observado no tratamento em que não foi aplicado herbicida. Quando a chuva foi simulada 168 horas após a aplicação dos herbicidas, houve diferença entre sulfentrazone e imazapic, e o herbicida sulfentrazone apresentou maior redução no número de bulbos. Em relação às épocas em que foi simulada a chuva, não houve diferença entre 24 e 168 horas para qualquer tratamento herbicida (Tabela 6).

Resultados semelhantes foram observados por Negrisoli et al. (2004). Os autores simularam chuva aos 55 dias após a aplicação de sulfentrazone e obtiveram excelente controle de $C$. rotundus, demonstrando assim uma possivel permanência do produto na palha de cana-de-açúcar.

Medeiros et al. (2004) desenvolveram experimento para avaliar a eficácia do herbicida imazapic no controle de tiririca em presença de palha de cana-de-açúcar e concluíram que, mesmo que após a aplicação do herbicida ocorra um período de seca de até 60 dias, a transposição do herbicida imazapic através da palha de cana, nas doses de 123 e $147 \mathrm{~g} \mathrm{ha}^{-1}$, é altamente significativa, independentemente da quantidade de água (10 ou $20 \mathrm{~mm}$ ) aplicada após a aplicação do herbicida.
Tabela 6 - Efeito da interação entre os herbicidas e a época em que foi simulada a chuva após a aplicação dos herbicidas no número de plantas, no número de bulbos basais e na massa seca de rizoma + raiz, aos 60 DAP. PiracicabaSP, 2005

\begin{tabular}{|c|c|c|}
\hline \multirow{2}{*}{ Herbicida } & \multicolumn{2}{|c|}{ Época em que foi simulada a chuva } \\
\hline & 24 horas & 168 horas \\
\hline & \multicolumn{2}{|c|}{ Número de plantas ${ }^{\underline{1}}$} \\
\hline Sem herbicida & $3,82 \mathrm{aA}^{2}{ }^{\prime \prime}$ & $3,75 \mathrm{aA}$ \\
\hline Sulfentrazone & $2,08 \mathrm{aB}$ & $1,45 \mathrm{aC}$ \\
\hline \multirow[t]{3}{*}{ Imazapic } & $1,65 \mathrm{aB}$ & $2,12 \mathrm{aB}$ \\
\hline & CV (\%) 31,24 & F 6,01 \\
\hline & \multicolumn{2}{|c|}{ Número de bulbos basais ${ }^{1 /}$} \\
\hline Sem herbicida & $3,93 \mathrm{aA}^{2} \stackrel{2}{\prime}^{\prime}$ & $3,87 \mathrm{aA}$ \\
\hline Sulfentrazone & $1,91 \mathrm{aB}$ & $1,43 \mathrm{aC}$ \\
\hline \multirow[t]{3}{*}{ Imazapic } & $1,93 \mathrm{aB}$ & $2,45 \mathrm{aB}$ \\
\hline & CV (\%) 35,72 & F 3,51 \\
\hline & \multicolumn{2}{|c|}{ Massa seca de rizoma + raiz } \\
\hline Sem herbicida & $1,23 \mathrm{aA}^{\frac{1 /}{}}$ & $0,94 \mathrm{aA}$ \\
\hline Sulfentrazone & $0,42 \mathrm{aB}$ & $0,16 \mathrm{aB}$ \\
\hline \multirow[t]{2}{*}{ Imazapic } & $0,15 \mathrm{aB}$ & $0,23 \mathrm{aB}$ \\
\hline & CV (\%) 71,73 & F 3,81 \\
\hline
\end{tabular}

1/ Médias seguidas por letras iguais, minúsculas na linha ou maiúsculas na coluna, não diferem entre si pelo teste de Tukey a $5 \%$. ${ }^{2 /}$ Os dados foram transformados em raiz de $\mathrm{x}+0,5$ para análise estatística.

A massa seca de rizoma + raiz foi afetada pelos herbicidas, tendo sido maior no tratamento em que não foi aplicado herbicida em qualquer época em que foi simulada a chuva. Os herbicidas sulfentrazone e imazapic causaram redução da massa seca de rizoma + raiz, mas não se diferenciaram entre si. Não houve diferença significativa entre as épocas em que foram simuladas as chuvas para quaisquer herbicidas (Tabela 6).

Pelos dados obtidos nas condições em que foi conduzida a presente pesquisa, pode-se concluir que: para o herbicida sulfentrazone, a presença de $20 \mathrm{t} \mathrm{ha}^{-1}$ de palha de cana-deaçúcar diminuiu a eficácia do herbicida; o herbicida imazapic teve bom desempenho tanto na ausência quanto na presença de palha e causou redução das variáveis estudadas independentemente da intensidade de chuva; a intensidade de chuva de $10 \mathrm{~mm}$ não foi suficiente para transpor o herbicida sulfentrazone na quantidade de $20 \mathrm{t} \mathrm{ha}^{-1}$ de palha - já a intensidade de $20 \mathrm{~mm}$ foi suficiente para lixiviar o herbicida até mesmo na maior quantidade de palha; e o herbicida sulfentrazone suporta 
mais a permanência na palha, pois apresentou melhor eficácia em relação ao imazapic quando a chuva foi simulada 168 horas após a aplicação dos herbicidas.

\section{AGRADECIMENTOS}

Aos funcionários do Departamento de Produção Vegetal da ESALQ/USP, Luiz Ferrari, Aparecido Mendes e Anderson Carneiro Polles, pela enorme ajuda na instalação e condução do experimento.

À Usina Costa Pinto - Grupo Cosan, em nome do Eng.-Agrônomo André Branquinho e do funcionário José Diniz Stenico, pela coleta de palha de cana-de-açúcar, solo e tubérculos.

\section{LITERATURA CITADA}

BENDIXEN, L. E.; NANDIHALLI, U. B. World wide distribution of purple and yellow nutsedge (Cyperus rotundus and C. esculentus). Weed Technol., v. 1, n. 1, p. 61-65, 1987.

CHRISTOFFOLETI, P. J.; LOPEZ OVEJERO, R. F.; NICOLAI, M. Manejo de plantas daninhas. Atualidades Agrícolas, p. 10-14, 2004.

CHRISTOFFOLETI, P. J. et al. Controle da planta daninha tiririca (Cyperus rotundus) na cultura da cana-de-açúcar através de herbicidas aplicados em condições de préemergência da cultura e da planta daninha. In: CONGRESSO BRASILEIRO DA CIÊNCIA DAS PLANTAS DANINHAS, 20., 1995, Florianópolis. Resumos... Florianópolis: Sociedade Brasileira da Ciência das Plantas Daninhas, 1995. p. 205-207.

CHRISTOFFOLETI, P. J.; DEGASPARI, N.; MEDEIROS, D. Redução do número de tubérculos e controle de tiririca (Cyperus rotundus L.) em cana soca com o uso de Plateau 70 DG (imazapic). In: CONGRESSO NACIONAL DA SOCIEDADE DOS TÉCNICOS AÇUCAREIROS E ALCOOLEIROS DO BRASIL, 8., 2002, Recife. Anais... Piracicaba: ESALQ, 2002. p. 137-142.

DURIGAN, J. C.; TIMOSSI, P. C.; LEITE, G. L. Controle químico da tiririca (Cypeurs rotundus), com e sem cobertura do solo pela palha de cana-de-açúcar. Planta Daninha, v. 22, n. 1, p. 127-135, 2004.

GOMIDE, M. B. Potencialidade alelopática dos restos culturais de dois cultivares de cana-de-açúcar (Saccharum sp.) no controle de algumas plantas daninhas. 1993. 96 p. Tese (Doutorado em Fitotecnia) - Escola Superior de Agricultura “Luiz de Queiroz", Piracicaba, 1993.
HERNANDEZ, D. D.; ALVES, P. L. C. A.; MARTINS, J. V. F. Influência do resíduo de colheita de cana-de-açúcar sem queima sobre a eficiência do imazapic e imazapic + pendimethalin. Planta Daninha, v. 9, n. 3, p. 419-426, 2001.

LORENZI, H. Tiririca - uma séria ameaça aos canaviais. Boletim Técnico Copersucar, n. 36, p. 3-10, 1986.

MARIM, C. D. et al. Washofl of herbicides applied to corn residue. Transactions of the ASAE, v. 21, p. 1164-1168, 1979.

MARTINS, D. et al. Emergência em campo de dicotiledôneas infestantes em solo coberto com palha de cana-de-açúcar. Planta Daninha, v. 17, n. 1, p. 151-161, 1999.

MEDEIROS, D. Efeitos da palha de cana-de-açúcar (Saccharum spp) sobre o manejo de plantas daninhas e dinâmica do banco de sementes. 2001. 126 f. Dissertação (Mestrado em Fitotecnia) - Escola Superior de Agricultura "Luiz de Queiroz", Piracicaba, 2001.

MEDEIROS, D; CHRISTOFFOLETI, P. J. Efeito da intensidade de chuva e da quantidade de palha de cana-deaçúcar sobre a eficácia de herbicidas. In: CONGRESSO BRASILEIRO DA CIÊNCIA DAS PLANTAS DANINHAS, 23., 2002, Gramado. Resumos... Londrina: IAPAR, 2002. p. 510 .

MEDEIROS, D. et al. Eficácia do herbicida imazapic no controle de tiririca (Cyperus rotundus) em presença de palha de cana-de-açúcar. In: CONGRESSO BRASILEIRO DA CIÊNCIA DAS PLANTAS DANINHAS, 24., 2004, São Pedro. Anais... São Pedro: Sociedade Brasileira da Ciência das Plantas Daninhas, 2004. CD-ROM.

NEGRISOLI, E. et al. Eficácia do sulfentrazone em diferentes doses associado à palha de cana-de-açúcar com ou sem chuva após a aplicação no controle de plantas daninhas. In: CONGRESSO BRASILEIRO DA CIÊNCIA DAS PLANTAS DANINHAS, 24., 2004, São Pedro. Anais... São Pedro: Sociedade Brasileira da Ciência das Plantas Daninhas, 2004. CD-ROM.

NOVO, M. C. S. S. Efeito da palha de cana-de-açúcar e do tamanho de tubérculos no desenvolvimento da tiririca (Cyperus rotundus). 2004. $107 \mathrm{f}$. Tese (Doutorado em Fitotecnia) - Escola Superior de Agricultura "Luiz de Queiroz", Piracicaba, 2004.

PROCÓPIO, S. O. et al. Manejo de plantas daninhas na cultura da cana-de-açúcar. Viçosa, MG: Universidade Federal de Viçosa, 2003. 150 p.

RODRIGUES, B. N. Influência da cobertura morta no comportamento dos herbicidas imazaquin e clomazone. Planta Daninha, v. 11, n. 1, p. 21-28, 1993. 
TEASDALE, J. R.; MOHLER, C. L. Light transmittance, soil temperature, and soil moisture under residue of hairy vetch and rye. Agron. J., v. 85, p. 673-680, 1993.

VELINI, E. D.; NEGRISOLI, E. Controle de plantas daninhas em cana crua. In: CONGRESSO BRASILEIRO DA CIÊNCIA DAS PLANTAS DANINHAS, 22., 2000, Foz do Iguaçu.

Palestras... Londrina: Sociedade Brasileira da Ciência das Plantas Daninhas, 2000. p. 148-164.
VICTÓRIA FILHO, R. Controle de plantas daninhas na cultura cana-de-açúcar. In: CÂMARA, G. M. S.; OLIVEIRA, E. A. M. Produção de cana-de-açúcar. Piracicaba: FEALQ, 1993. p. 174-183.

VICTORIA FILHO, R.; CHRISTOFFOLETI, P. J. Manejo de plantas daninhas e produtividade da cana. Visão Agrícola, v. 1, n. 1, p. 32-37, 2004. 